\title{
Analisis Strategi Pemasaran Pada Hotel Bintang III Dalam Situasi Pandemi COVID-19
}

\author{
Syah Riza Octavy Sandy ${ }^{1}$, Juhanda ${ }^{2}$ \\ ProgramStudi Perhotelan, Fakultas Ilmu Sosial dan Ilmu Politik \\ Universitas Muhammadiyah Jember, Indonesia \\ Email : syahriza@unmuhjember.ac.id
}

\begin{abstract}
Abstrak
Penelitian ini akan membahas tentang Analisis Strategi Pemasaran Pada Hotel Bintang III Dalam Situasi Pandemi Covid-19 ( Studi Kasus Hotel Bintang III Di Kabupaten Jember). Sehingga melalui penelitian ini dapat memberikan referensi pemikiran kepada mitra stakeholder yaitu asosiasi PHRI (Persatuan Hotel dan Restoran Indonesia) Cabang Jember dan lebih khusus kepada pelaku usaha jasa perhotelan sebagai acuan dalam mengambil kebijakan dalam menyikapi strategi pemasaran hotel pada situasi pandemic Covid 19.Penelitian ini bertujuan untuk mengetahui dan menganalisa strategi yang paling tepat dalam situasi Pandemi Covid 19 (Studi Kasus Hotel Bintang III Di Kabupaten Jember).Populasi dari penelitian ini adalah General Manajer \& Manajer Pemasaran dan pihak terkait (Studi Kasus Hotel Bintang III Di Kabupaten Jember). Tahapan kegiatan ini dimulai dengan survei, yaitu, penyelidikan instrumen uji. Setelah mendapatkan instrumen yang valid, tim peneliti semakin berkurang untuk mengeksplorasi informasi dengan wawancara dan penyebaran kuesioner untuk mendapatkan data primer dan sekunder. Kesimpilan penelitian ini adalah (1) Keadaan persaingan berpengaruh terhadap hotel masa pandemi di Jember; (2) Perkembangan teknologi berpengaruh terhadap hotel masa pandemi di Jember; (3) Kebijakan politik dan ekonomi berpengaruh terhadap hotel masa pandemi di Jember; (4) Perubahan demografi berpengaruh terhadap hotel masa pandemi di Jember; (5) Perkembangan teknologi berpengaruh dominan terhadap hotel masa pandemi di Jember.
\end{abstract}

Kata Kunci : Strategi Pemasaran, Hotel, Pandemi Covid-19

\begin{abstract}
This study will discuss the Analysis of Marketing Strategies at III Star Hotels in a Covid-19 Pandemic Situation (Case Study of III Star Hotels in Jember Regency). So that through this research, it can provide a reference of thought to stakeholder partners, namely the PHRI Association (Indonesian Hotel and Restaurant Association) Jember Branch and more specifically to hotel service business actors as a reference in making policies in responding to hotel marketing strategies in the Covid 19 pandemic situation. to find out and analyze the most appropriate strategy in the Covid 19 Pandemic situation (Case Study of III Star Hotels in Jember Regency). The population of this study was General Managers \& Marketing Managers and related parties (Case Study of III Star Hotels in Jember Regency). This activity stage begins with a survey, namely, an investigation of the test instrument. After obtaining a valid instrument, the research team was reduced to exploring information by interviewing and distributing questionnaires to obtain primary and secondary data. The conclusions of this study are (1) The state of competition has an effect on hotels during the pandemic in Jember; (2) Technological developments affect hotels during the pandemic in Jember; (3) Political and economic policies affect hotels during the pandemic in Jember; (4) Demographic changes affect hotels during the pandemic in Jember; (5) Technological developments have a dominant influence on hotels during the pandemic in Jember
\end{abstract}

Keywords: Marketing Strategy, Hotel, Covid-19 Pandemic 


\section{PENDAHULUAN}

Industri hotel adalah salah satu sektor terparah yang terdampak pandemi covid-19. Menurut laporan Hotels News Now, sektor perhotelan telah kehilangan 5 juta pekerja sejak Februari, Angkanya tentu berkali lipat bila penghitungan dilakukan secara global. Hunian hotel dalam beberapa kasus turun sebanyak $95 \%$ bila dibandingkan dengan tahun

lalu.(https://www.blackxperience.com/blacka ttitude/blackspot/industri-hotel-di-masapandemi)

Hampir seluruh sektor usaha, baik barang dan jasa terdampak oleh pandemi covid-19 saat ini, salah satu sector itu adalah usaha sector jasa perhotelan. Kondisi ketidakpastian dan maraknya pembatasan oleh Pemerintah menjadikan jumlah konsumen atau kunjungan hotel mengalami penurunan yang signifikan, dimana tingkat keterisian hotel menurun50-70 \% dibandingkan sebelumnya atau keterisian hotel hanya mencapai $10-20 \%$. Pada periode Juli-Agustus, Pemerintah telah melonggarkan aturan pembatasan sosial, meskipun pandemi Covid-19 belum usai. Banyak orang mulai kembali bekerja, bertemu dengan teman maupun keluarga, pertokoan dan perhotelan yang mulai kembali beroperasi untuk menerima tamu.

Pandemi Covid 19 Strategi pemasaran ini adalahhal yang sangat penting untuk dilakukan. Untuk hasil yang optimal, strategi pemasaran memiliki jangkauan luas, terutama berdasarkan persaingan, strategi, strategi produk, strategi layanan dan lainnya.

Perusahaan harus mengenali kekuatan dan kelemahan perusahaan, akan sangat berguna untuk mengenali dan memanfaatkan setiap kesempatan dan menghindari atau meminimalkan risiko. Perusahaan harus mengenali kekuatan dan kelemahanp erusahaanuntukpiniers, akan sangat berguna untuk mengenali dan dapat mengambil keuntungan dari setiap kesempatan yang ada dan untuk menghindari atau meminimalkan risiko yang ada.
Kenyamanan dan keamanan menjadi tuntutan utama bagi penggunajasaperhotelan pada saat pandemi Covid-19 ini, persoalaniniditambahlagidenganadanyatingk atpersaingan yang semakin tajam antar sesama pengelola bisnis perhotelan. Kedua factor ini menuntut setiap pengelola di industri perhotelan ini selalu meningkatkan kualitas pelayanannnya untuk menjadi pilihan pertama bagi pengunjung sebagai pengguna jasa. Bisnis hotel saat pandemi seperti ini cenderung menurun, hal ini sangat bergantung pada kepercayaan dan rasa aman kepada pengunjung serta pelayanan yang sudah umum diberikan karyawan kepada pengunjung.

Pengelola bisnis perhotelan yang terdampak pandemi ini harus menyusun strategi dalam rangka mengembalikan kepercayaan pengunjung saat pandemi, Sehingga dapat menyusun strategi pemasaran saat pandemi ini.

\section{METODOLOGI}

Variabel Penelitian

Adapum variabel penelitian yang diamati adalah:

Variabel X : strategi pemasaran

Varibel Y : hotel masa pandemi

Jenis dan Sumber Data

Data Primer.

Sumber data primer adalah data yang diperoleh langsung oleh penulis sumber pertama atau responden langsung. Adapun data tersebut diperoleh dari berbagai cara, antara lain: observasi, wawancara dan angket atau kuesioner yang disebarkan langsung secara acak kepada General Manajer dan Manajer Pemasaran dan lainya .

Data Sekunder

Data sekunder adalah data pendukung dari penelitian yang dilakukan. Data ini diperoleh dari beberapa sumber yaitu studi-studi kepustakaan, serta data-data yang diperoleh dari hotel di kabupaten Jember. yang berbentuk dokumen-dokumen atau laporanlaporan tertentu yang berkaitan dengan penelitian ini. 


\subsection{Metode Pengumpulan Data}

Dalam penelitian ini, data dikumpulkan dengan metode berikut:

Pengamatan

Pengumpulan data dengan melakukan pengamatan langsung di lokasi pencarian untuk mendapatkan gambar yang jelas dari objek yang diteliti dalam hal ini adalah sebuah hotel di tengah-tengah penelitian ini.

Pemeliharaan terstruktur.

Pengumpulan data dengan wawancara langsung dengan pihak-pihak terkait dalam hal ini manajer hotel di Jember, staf hotel

Studi Perpustakaan

Yaitu, pengumpulan data dengan menggunakan beberapa buku sebagai referensi atau sumber diskusi, khususnya teori atau konsep yang relevan untuk masalah yang dibahas.

\section{Metode Analisis Data}

Tahap Analisis Data

Tahap analisis data merupakan usaha untuk memecahkan suatu masalah dan hipotesis dalam suatu penelitian. Agar tujuan dalam penelitian ini dapat tercapai maka dilakukan analisis data sebagai berikut :

Regresi Linier Berganda

Digunakan untuk mengetahui besarnya pengaruh Starategi Pemasaran, , Keadaan Persaingan, Teknologi, Kebijakan politik \& ekonomi, perubahan demografi fasilitas kamar, aksesibilitas (variabel bebas). Hotel masa pandemic (variabel terikat) yang formulasinya sebagai berikut (Supranto, 2001:236)

$\mathrm{Y}=\mathrm{a}+\mathrm{b} 1 \mathrm{X} 1+\mathrm{b} 2 \mathrm{X} 2+\mathrm{b} 3 \mathrm{X} 3+\mathrm{b} 4 \mathrm{X} 4+\mathrm{e}$ Keterangan:

$\begin{array}{ll}\mathrm{Y} & =\text { Hotel } \\ \mathrm{a} & =\text { Konstanta } \\ \mathrm{b} 1 \ldots \mathrm{b} 4 & = \\ \mathrm{X} 1 & =\text { Keadaan persaingan } \\ \mathrm{X} 2 & =\text { Perkembangan teknologi } \\ \mathrm{X} 3 & =\text { Kebijakan politik dan } \\ & \text { ekonomi } \\ \mathrm{X} 4 & =\text { Perubahan demografik } \\ \mathrm{e} & =\text { variabel gangguan }\end{array}$

Analisis regresi dilakukan sebagai uji statistik dalam rangka mengetahui strategi pemasaran pada masa pandemi.

Pengujian Terhadap Hipotesis Penelitian yang Diajukan

Uji signifikansi komponen strategi pemasaran pada masa pandemi) terhadap hotel di Kota Jember (variabel terikat) secara simultan akan diuji dengan uji $F$ (F-test), sedangkan secara serentak akan diuji dengan uji statistik t (t-test). Adapun langkahlangkahnya sebagai berikut:

a). Pengujian dengan Uji F-Statistik

Uji F dimaksudkan untuk menguji hipotesis yang berguna untuk menguji signifikasi pengaruh variabel-variabel independen secara simultan terhadap variabel dependen. Uji F-Statistik digunakan secara serentak terhadap Strategi Pemasaran hotel di Kota Jember, dengan tahapan sebagai berikut :

(1). Menentukan nilai F-hitung dengan rumus : (Rangkuti, 1997:165)

Fhitung $=$

Keterangan :

$\mathrm{F} \quad=$ pengujian statistik

$\mathrm{R} 2=$ koefisien determinasi

$\mathrm{K}=$ jumlah variabel

$\mathrm{N} \quad=$ jumlah sampel

(2). Menentukan Hipotesis

Ho $=\square \mathrm{i}=0 \quad$ Variabel-variabel bebas secara simultan tidak mempunyai pengaruh yang signifikan terhadap variabel terikat

$\mathrm{Hi}=\square \mathrm{i} \square 0 \quad$ Variabel-variabel bebas secara simultan mempunyai pengaruh yang signifikan terhadap variabel terikat

(3). Menentukan tingkat signifikansi

Tingkat signifikansi yang diharapkan adalah $\square=5 \%$ atau confidentinterfal $95 \%$

(4). Kriteria pengujian untuk pengujian dua sisi :

(a). Dengan membandingkan statistik hitung dengan statistik tabel

Jika statistik Fhitung $\neg<$ statistik Ftabel, maka Ho diterima

Jika statistik Fhitung> statistik Ftabel, maka Ho ditolak

(b). Berdasarkan Probabilitas 
Jika probabilitas $>0,05$, maka Ho diterima Jika probabilitas $<0,05$, maka Ho ditolak

b). Pengujian dengan Uji t-Statistik

Uji t-Statistik digunakan untuk menguji pengaruh dari strategi pemasaran pada masa pandemi hotel di Kota Jember, dengan tahapan sebagai berikut:

(1). Menentukan t-statistik dengan rumus : (Supranto, $2001:$ 188)

$$
\mathrm{t}=
$$

Keterangan:

$\mathrm{b}=$ koefisien regresi parsial variabel

$\mathrm{B}=$ koefisien regresi parsial populasi

$\mathrm{Sb}=$ standar error koefisien regresi

(2). Merumuskan Hipotesis

$\mathrm{Ho}=\square \mathrm{i}=0 \quad$ variabel independen tidak mempunyai pengaruh yang signifikan terhadap variabel dependen

$\mathrm{Hi}=\square \mathrm{i} \square 0 \quad$ variabel independen mempunyai pengaruh yang signifikan terhadap variabel dependen

(3). Menentukan tingkat signifikan

Tingkat signifikansi yang diharapkan adalah $5 \%$, uji dua arah yaitu ttabel pada $\square / 2==$ 0,025 atau confident interval.

(4). Kriteria pengujian untuk pengujian 2 sisi (a). Dengan membandingkan statistik hitung dengan statistik tabel

Jika statistik thitung $<$ statistik ttabel, maka Ho diterima

Jika statistik thitung> statistik ttabel, maka Ho ditolak

(b). Berdasarkan Probabilitas

Jika probabilitas $>0,05$, maka Ho diterima

Jika probabilitas $<0,05$, maka Ho ditolak

\section{HASIL DAN PEMBAHASAN}

\section{a. Analisis Deskriptif Variabel Penelitian}

Deskripsi variabel penelitian berguna untuk mendukung hasil analisis data. Hasil analisis statistik deskriptif dapat disarikan dalam tabel berikut :

Tabel 1. AnalisisDeskriptif Skor JawabanResponden
Tabel 5.1 Analisis Deskrip tif Skor Jawab an Responden

\begin{tabular}{|c|c|c|c|c|}
\hline Variabel & Indikator & Mean & Modus & Kategori Variabel \\
\hline \multirow{5}{*}{$\begin{array}{c}\text { Keadaan persaingan } \\
\text { (X1) }\end{array}$} & $\mathrm{X} 1.1$ & 4,00 & 4 & \multirow{5}{*}{ Baik } \\
\hline & $\mathrm{X} 1.2$ & 4,06 & 4 & \\
\hline & $\mathrm{X} 1.3$ & 3,88 & 4 & \\
\hline & $\mathrm{X} 1.4$ & 4,06 & 4 & \\
\hline & $\mathrm{X} 1$ & 4,00 & 4 & \\
\hline \multirow{6}{*}{$\begin{array}{l}\text { Perkembangan } \\
\text { teknologi (X2) }\end{array}$} & $\mathrm{X} 2.1$ & 3,91 & 4 & \multirow{6}{*}{ Baik } \\
\hline & $\mathrm{X} 2.2$ & 3,81 & 4 & \\
\hline & $\mathrm{X} 2.3$ & 3,59 & 3 & \\
\hline & $\mathrm{X} 2.4$ & 4,06 & 4 & \\
\hline & $\mathrm{X} 2.5$ & 4,00 & 4 & \\
\hline & $\mathrm{X} 2$ & 3,88 & 4 & \\
\hline \multirow{6}{*}{$\begin{array}{l}\text { Kebijakan politik dan } \\
\text { ekonomi (X3) }\end{array}$} & $\mathrm{X} 3.1$ & 3,94 & 4 & \multirow{6}{*}{ Baik } \\
\hline & $\times 3.2$ & 3,84 & 4 & \\
\hline & $\mathrm{X} 33$ & 4,03 & 4 & \\
\hline & $\times 3.4$ & 4,00 & 4 & \\
\hline & $\times 3.5$ & 3,97 & 4 & \\
\hline & $\mathrm{X} 3$ & 3,96 & 4 & \\
\hline \multirow{5}{*}{$\begin{array}{l}\text { Perubahan demografi } \\
\text { (X4) }\end{array}$} & $\mathrm{X} 4.1$ & 3,66 & 4 & \multirow{5}{*}{ Cukup Baik } \\
\hline & $\mathrm{X} 4.2$ & 3,53 & 3 & \\
\hline & $\mathrm{X} 4.3$ & 3,81 & 3 & \\
\hline & $\mathrm{X} 4.4$ & 3,50 & 3 & \\
\hline & $\mathrm{X} 4$ & 3,63 & 3 & \\
\hline \multirow{5}{*}{$\begin{array}{l}\text { Hotel masa pandemi } \\
\text { (Y) }\end{array}$} & Y1 & 3,88 & 4 & \multirow{5}{*}{ Baik } \\
\hline & Y2 & 3,59 & 4 & \\
\hline & Y3 & 3,72 & 4 & \\
\hline & Y4 & 3,69 & 4 & \\
\hline & $Y$ & 3,72 & 4 & \\
\hline
\end{tabular}

Berdasarkan Tabel 5.1 dapat dinyatakan berkaitan dengan variabel keadaan persaingan (X1) dipersepsikan "baik" oleh sebagian besar responden yang dibuktikan dengan diperolehnya nilai mean secara keseluruhan 4,00 dan modus sebesar 4 . Baiknya persepsi terhadap variabel keadaan persaingan dapat dilihat melalui banyaknya hotel yang menjalankan bisnisnya di Jember, adanya hotel yang menawarkan inovasi produk dan layanan, hotel pesaing menawarkan kebijakan diskon, dan hotel melakukan kerjasama dengan berbagai vendor sebagai akses ke saluran pemasaran.

Berkaitan dengan variabel perkembangan teknologi (X2) dipersepsikan "baik" oleh sebagian besar responden yang dibuktikan dengan diperolehnya nilai mean secara keseluruhan 3,88 dan modus sebesar 4 . Baiknya persepsi terhadap variabel perkembangan teknologi dapat dilihat melalui perkembangan internet yang semakin pesat dan menunjang usaha hotel, masyarakat semakin terbiasa menggunakan teknologi termasuk dalam perilaku memilih hotel, kemajuan teknologi cukup membuka peluang inovasi pemasaran hotel, anggaran $\mathrm{R} \& \mathrm{D}$ dinilai mampu mendorong peningkatan pemasaran hotel, dan adanya teknologi dapat mempermudah akses pemasaran hotel. 
Berkaitan dengan variabel kebijakan politik dan ekonomi (X3) dipersepsikan "baik" oleh sebagian besar responden yang dibuktikan dengan diperolehnya nilai mean secara keseluruhan 3,96 dan modus sebesar 4. Baiknya persepsi terhadap variabel kebijakan politik dan ekonomi dapat dilihat melalui kondisi politik dan keamanan baik nasional maupun regional terjaga, kebijakan perundang-undangan dan peraturan daerah mendukung bisnis, hubungan dunia usaha dan pemerintah berjalan dengan baik, stabilitas ekonomi yang terjaga mendukung dunia usaha, dan iklim usaha yang stabil.

a. Berkaitan dengan variabel perubahan demografi (X4) dipersepsikan "cukup baik" oleh sebagian besar responden yang dibuktikan dengan diperolehnya nilai mean secara keseluruhan 3,63 dan modus sebesar 3. Cukup baiknya persepsi terhadap variabel perubahan demografi dapat dilihat melalui terjadinya pergeseran tingkat pendapatan masyarakat menjadi lebih tinggi, peningkatan jumlah kelompok masyarakat yang memiliki daya beli tinggi, perubahan gaya hidup masyarakat menjadi peluang dalam pemasaran hotel, dan perlunya melakukan identifikasi aspek demografi dalam menangkap peluang pemasaran hotel.

b. Berkaitan dengan variabel hotel masa pandemi (Y) dipersepsikan "baik" oleh sebagian besar responden yang dibuktikan dengan diperolehnya nilai mean secara keseluruhan 3,72 dan modus sebesar 4 . Baiknya persepsi terhadap variabel hotel dapat dilihat melalui usaha pemasaran hotel berjalan secara efektif, hotel mampu menjalankan usaha secara efisien, biaya operasional hotel lebih kecil dibandingkan dari biaya penjualan, dan tujuan perusahaan baik jangka pendek maupun jangka panjang tercapai.

\section{c. Analisis Regresi Linier Berganda}

Pengujian regresi linear berganda berguna untuk mengetahui tingkat pengaruh variabel independen (keadaan persaingan, perkembangan teknologi, kebijakan politik dan ekonomi, dan perubahan demografi) terhadap variabel dependen (hotel masa pandemi). Berdasarkan pengujian diperoleh hasil yang dapat disajikan dalam tabel berikut.

Tabel 2. Hasil Perhitungan Regresi Linear Berganda

\begin{tabular}{|c|c|c|c|c|}
\hline Variabel & $\begin{array}{r}\text { Koef. } \\
\text { Regresi }\end{array}$ & thäbmg & Sig. & Keterangan \\
\hline Konstanta & $-10,768$ & $-2,900$ & 0,007 & - \\
\hline $\mathrm{X} 1$ & 0,419 & 3,390 & 0,002 & Signifikan \\
\hline $\mathrm{x} 2$ & 0,470 & 4,109 & 0,000 & Signifikan \\
\hline $\mathrm{x} 3$ & 0,353 & 3,185 & 0,004 & Signifikan \\
\hline \multirow[t]{8}{*}{$\mathrm{X} 4$} & 0,197 & 2,241 & 0,033 & Signifikan \\
\hline & & & $\mathrm{R}$ & 0,808 \\
\hline & & & $\mathrm{R}^{2}$ & 0,653 \\
\hline & & & $F_{\text {hitm }}$ & 12,681 \\
\hline & & & & 0,000 \\
\hline & & & $F$ & 32 \\
\hline & & & Sig. & \\
\hline & & & $\mathrm{n}$ & \\
\hline
\end{tabular}

Berdasarkan tabel diatas, maka persamaan regresi linier berganda yang diperoleh adalah:

$\mathrm{Y}=-10,768+0,419 \mathrm{X} 1+0,470 \mathrm{X} 2+$ $0,353 \mathrm{X} 3+0,197 \mathrm{X} 4$

1. Interpretasi atas hasil analisis tersebut dapat dinyatakan sebagai berikut:

2. Konstanta sebesar $-10,768$, menunjukkan besarnya hotel masa pandemi pada saat variabel keadaan persaingan, perkembangan teknologi, kebijakan politik dan ekonomi, dan perubahan demografi sama dengan nol. Dalam hal ini hotel masa pandemi mengalami penurunan tanpa keempat variabel tersebut yang disebabkan oleh faktor lain.

3. $\mathrm{b} 1=0,419$, artinya apabila variabel perkembangan teknologi, kebijakan politik dan ekonomi, dan perubahan demografi sama dengan nol, maka peningkatan variabel keadaan persaingan sebesar satu satuan akan meningkatkan hotel masa pandemi sebesar 0,419 satuan.

4. $\mathrm{b} 2=0,470$ artinya apabila variabel keadaan persaingan, kebijakan politik dan ekonomi, dan perubahan demografi sama dengan nol, maka peningkatan variabel perkembangan teknologi sebesar satu satuan akan meningkatkan hotel masa pandemi sebesar 0,470 satuan.

5. $\mathrm{b} 3=0,353$ artinya apabila variabel keadaan persaingan, perkembangan teknologi, dan perubahan demografi 
sama dengan nol, maka peningkatan variabel kebijakan politik dan ekonomi sebesar satu satuan akan meningkatkan hotel masa pandemi sebesar 0,353 satuan.

6. $\mathrm{b} 4=0,197$ artinya apabila variabel keadaan persaingan, perkembangan teknologi, dan kebijakan politik dan ekonomi sama dengan nol, maka peningkatan variabel perubahan demografi sebesar satu satuan akan meningkatkan hotel masa pandemi sebesar 0,197 satuan.

\section{d. AnalisisKoefisienDeterminasiBerganda $\left(\mathbf{R}^{2}\right)$.}

Nilai koefisien determinasi berganda (R2) dimaksudkan untuk mengetahui besarnya sumbangan dari variable bebas terhadap variable terikat. Berdasarkan hasil analisis yang bias dilihat pada Tabel 5.2 diperoleh hasil koefisien determinasi berganda (R2) sebesar 0,653, haliniberarti $65,3 \%$ perubahan hotel masa pandemic dipengaruhi oleh variable keadaan persaingan, perkembangan teknologi, kebijakan politik dan ekonomi, dan perubahan demografi sedangkan sisanya sebesar $34,2 \%$ disebabkan oleh faktor lain sepertibauranpemasaran, protocol kesehatan, dan lainnya yang tidak termasuk dalampersamaan regresi yang dibuat.

\section{e. PengujianHipotesis}

\section{Hasil Uji F}

Pengujian ini bertujuan untuk mengetahui pengaruh variable keadaan persaingan, perkembangan teknologi, kebijakan politik dan ekonomi, dan perubahan demografi terhadap hotel masa pandemic secara bersama-sama. Berdasarkan Tabel 5.2 dapat dilihat bahwa nilai $\mathrm{F}$ hitung sebesar 12,681 lebih besar daripada $\mathrm{F}$ tabel $(2,71)$ dan nilai probabilitas (P value $)<0,05$ atau $(0,000<0,05)$ maka dinyatakan keadaan persaingan, perkembangan teknologi, kebijakan politik dan ekonomi, dan perubahan demografi terbukti berpengaruh secara bersama-sama terhadap hotel masa pandemidi Jember.

2. Hasil Uji t keputusan berkunjung Tamu Pada saat Pandemi Covid19 di kota Jember.

3. Hasil Analisis Koefisien Korelasi Parsial $\left(\mathrm{r}_{\text {partial }}\right)$

Analisis koefisien korelasi parsial digunakan untuk mengetahui variabel bebas mana yang dominan terhadap variabel terikat yaitu dengan melihat variabel yang memiliki nilai thitung tertinggi serta nilai signifikansi (sig.) terkecil. Berdasarkan hasil tersebut, dapat disimpulkan bahwa dari keempat variabel (keadaan persaingan, perkembangan teknologi, kebijakan politik dan ekonomi, dan perubahan demografi) yang memiliki pengaruh dominan terhadap hotel masa pandemi di Jember adalah variabel perkembangan teknologi (X2).

Pihak hotel senantiasa dituntut untuk mampu meningkatkan kemampuan staf hotel dan aspek ini akan menjadi penentu bagi tamu dalam memutuskan untuk mengunjungi dan menggunakan jasa hotel.

\section{KESIMPULAN}

Berdasarkan hasil analisis, maka dapat diambil kesimpulan sebagai berikut:

1. Keadaan persaingan berpengaruh terhadap hotel masa pandemi di Jember.

2. Perkembangan teknologi berpengaruh terhadap hotel masa pandemi di Jember.

3. Kebijakan politik dan ekonomi berpengaruh terhadap hotel masa pandemi di Jember.

4. Perubahan demografi berpengaruh terhadap hotel masa pandemi di Jember.

5. Perkembangan teknologi berpengaruh dominan terhadap hotel masa pandemi di Jember.

\section{DAFTAR PUSTAKA}

Agusnawar, A.Md.Par. 2002. Pengantar Operasional Kantor Depan Hotel. PT. Perca, Jakarta

Darsono Agustinus. 2001. Kantor Depan Hotel. PT.GramediaWidiasarana Indonesia: Jakarta

Handoko T. Hadi. 2000. Manajemen Personalia Dan Sumberdaya Manusia. BPFE: Yogyakarta 
https://id.wikipedia.org/wiki/Pandemi_COVI D-19, ( akses agustus 2020)

Mustika Zed, Metode Penelitian Kepustakaan, Jakarta: Yayasan Obor Nasional, 2004

Rangkuti, Freddy. 2001. Analisis SWOT Teknik Membedah Kasus Bisnis. Jakarta : Gramedia Pustaka Utama.

Soekadijo. R. G. 2000. Anatomi Pariwisata. Jakarta : PT Gramedia Pustaka Umum.

Ir, MM. 1997. Operasional Kantor Depan. PT. Gramedia Pustaka Utama: Jakarta.

Sugiarto Endar, Ir, MM. 1996. Pengantar Akomodasi Dan Restoran. PT. Gramedia Pustaka Utama: Jakarta

Swastha, Basu dan Irawan. 1997. Manajemen Pemasaran Modern. Edisi kelima, Yogyakarta : Liberty.

Tjiptono, Fandi. 2001. "Strategi Pemasaran". Edisi kedua, Yogyakarta : Andi

Wahab, Salah. 1997. Pemasaran Pariwisata. Jakarta : PT. Pradya Paramitha.

Yoeti, Oka. 1996. Pemasaran Pariwisata, Bandung : Angkasa Bandung.

Anwari Masatip, Ita Maemunah, Dina Rosari, Christina Anggreani Analisis Strategi Pemasaran pada Hotel Inna Parapatdalam Situasi Pandemi Covid-19

Arif, M Nur Rianto Al.2012. Lembaga Keuangan Syariah. Bandung: CVPustaka.Moleong,Lexy. (2005).
Metodologi Penelitian Kualitatif. Bandung: PT Remaja.Spillane,James. 1994. Pariwisata Indonesia, Siasat Ekonomi dan Rekayasa Kebuadayaan. Kanisius. Yogyakarta.Tjiptono, Fandy.2014,

Pemasaran Jasa-Prinsip, Penerapan, dan Penelitian, Andi. Offset, Yogyakarta 